\title{
Evaluation of Risk Factors and Changes in Liver Enzymes among the Patients with Antituberculosis Drug-Induced Hepatitis: A Teaching Hospital Based Study
}

\author{
Omparkash Dhania ${ }^{1}$ \\ ${ }^{1}$ Assistant Professor, Department of Tuberculosis \& Respiratory Diseases, World College of Medical Sciences Research and Hospital, Gurawar, Jhajjar-124103.
}

\section{Abstract}

Background: Tuberculosis remains a major global health problem despite the availability of highly efficacious treatment for decades. Subjects and Methods: Tuberculosis was diagnosed through bacteriological and histopathological methods. Bacteriological testing was based on three sputum samples or if the patient could not give the sample, three gastric aspiration samples were examined. The sputum were evaluated for Acid Fast Bacilli (AFB) by Ziehl-Neelsen staining. Results: The patients with DIH, one patient were treated with five anti-TB drugs because of relapse or treatment failure; $47 \%$ had ALT, AST $\geq 6$ times of ULN. These patients had loss of appetite (80\%), icterus (20\%), nausea (80\%), vomiting (50\%), malaise (45\%), right upper quadrant tenderness (24\%), and loss of consciousness (2\%). Liver enzyme levels were normal after four to 30 days. Conclusion: The frequency of DIH in the current study was higher than those of other studies, similar to other reports, most of the TB cases in which hepatotoxicity developed occurred in the subjects above 51 years old and a lot of them occurred after the first month of treatment.

Keywords: Tuberculosis, Acid Fast Bacilli and Drug-induced hepatitis.

Corresponding Author: Dr. Omparkash Dhania, Assistant Professor, Department of Tuberculosis \& Respiratory Diseases, World College of Medical Sciences Research and Hospital, Gurawar, Jhajjar. Harayana-124103.

Received: May 2019

Accepted: June 2019

\section{Introduction}

Tuberculosis (TB) remains a major global health problem despite the availability of highly efficacious treatment for decades. World Health Organization (WHO) declared TB a global public health emergency in 1993, at a time when an estimated 7-8 million new cases and 1.3-1.6 million deaths occurred each year. In 2010, there was an estimated 8.8 million new cases reported and 1.4 million deaths including deaths from TB among HIV-positive people. In India, TB is a major public health issue with an estimated prevalence of 256 per 100,000 population and 26 per 100,000 population dying of TB. ${ }^{[1]}$ Although about $85 \%$ of $\mathrm{TB}$ cases are successfully treated, treatment-related adverse events including hepatotoxicity, skin reactions, gastrointestinal and neurological disorders account for significant morbidity leading to reduced effectiveness of therapy. Hepatotoxicity is the commonest of all adverse effect leading to drug discontinuation in $11 \%$ of patients treated with combination of isoniazid, rifampicin and pyrazinamide. ${ }^{[2]}$ Employing multidrug regimens such as the combination of isoniazid, rifampin and pyrazinamide (INH, RIF and PZA) to treat Tuberculosis (TB) is associated with an increased incidence of drug-induced hepatitis (DIH). ${ }^{[3-5]}$ Risk factors of hepatotoxicity progression due to anti-tuberculosis (anti-
TB) treatment include chronic liver disease, active alcohol use, extensive pulmonary tuberculosis (PTB), old age, and genetic factors. ${ }^{[5]}$ Infection with hepatitis $\mathrm{B}$ and $\mathrm{C}$ viruses are common causes of chronic liver disease frequently observed in populations at risk for TB infection. The mechanisms of drug-induced hepatotoxicity from anti-TB agents are thought to involve direct cytotoxicity and an immune-related component especially by two main drugs (INH and RIF). ${ }^{[6]}$ According to different populations, the incidence of acute liver injury during standard anti-TB treatment is reported, varying from $1 \%$ to more than $31 \% .^{[5-}$ 11] This present study was to estimate the incidence of DIH in WCMSRH, Jhajjar.

\section{Subjects and Methods}

This Present study was conducted in the Department of TB and Chest, World College of Medical Sciences Research and Hospital, Jhajjar, during the period from December, 2016 to March, 2019. Tuberculosis was diagnosed through bacteriological and histopathological methods. Bacteriological testing was based on three sputum samples or if the patient could not give the sample, three gastric aspiration samples were examined. The sputum were evaluated for Acid Fast Bacilli (AFB) by Ziehl-Neelsen 
staining. All patients were treated with the standard regimen (a combination of IND, RIF, PZA and ethambutol (ETB) \pm streptomycin). Drug related hepatotoxicity was defined as increase in serum alanine aminotransferase $\geq 3$ ULN with symptoms of hepatitis, or more than five times of ULN with or without symptoms of hepatitis. The risk fac-tors and other co-morbidities such as Hepatitis B Virus (HBV), Hepatitis C Virus (HCV), and Human Immunodeficiency Virus (HIV) infection, diabetes, and use of other hepatotoxic drugs, and clinical course of drug hepatitis were also studied. When the patients showed DIH, their drugs were discontinued and according to the national protocol for the treatment of DIH, all drugs were gradually resumed. The statistical analysis of the results was carried out using SPSS version 18 to evaluate the significant differences; $\mathrm{P} \leq$ 0.05 .

\section{Diagnosis of drug-induced liver injury:}

The diagnostic criteria for drug-induced hepatitis (DILI) are as follows. ${ }^{[5]}$ : (1) A rise of five times the upper limit of normal levels (50 IU/1) of serum aspartate aminotransferase (AST) and/or alanine aminotransferase (ALT); (2) a rise in the level of serum total bilirubin $>1.5 \mathrm{mg} / \mathrm{dl}$; (3) any increase in AST and/or ALT above pre-treatment levels together with anorexia, nausea, vomiting, and jaundice; (4) absence of serologic evidence of infection with hepatitis virus $\mathrm{A}, \mathrm{B}$, or $\mathrm{C}$. Viral hepatitis markers (HBsAg, IgM anti$\mathrm{HAV}$, IgM anti-HBc, and anti-HCV second-generation antibodies) were analyzed using ELISA immunoassay kits. The presence of any one of the first three criteria along with the absence of viral hepatitis was considered to be having DILI. Patients with associated chronic illnesses such as cirrhosis of the liver, chronic hepatitis, acute viral hepatitis, gastro-intestinal, renal or cardiac diseases were excluded.

\section{Drug dosages:}

The drug dosages were calculated in relation to the weight of the patients as follows:

- Streptomycin: 0.75 gm IM (<50 years) and 0.50 gm (>50 years)

- Rifampicin: Body weight <450 mg/day; >50 kg - $600 \mathrm{mg}$

- Isoniazid: $600 \mathrm{mg}(10-15 \mathrm{mg} / \mathrm{kg})$

- Ethambutol: $1200 \mathrm{mg}(30 \mathrm{mg} / \mathrm{kg})$

- Pyrazinamide: 1500 mg (30-35mg/kg).

\section{Results\&Discussion}

The current study was conducted in the Department of TB and Chest, World College of Medical Sciences Research and Hospital during Two years. Among the 36 patients with TB (46\% Males; $54 \%$ Females in fig. 1) 7 patients (4 males, 3 females, and mean of age 22 - 67 years) were hospitalized due to anti-TB drug-induced hepatitis. Of the 7 patients with anti-TB drug-induced hepatitis, $67 \%$ were above 51 years; $20 \%$ of the cases occurred within the first two weeks after the treatment onset. Time range for developing DIH was 3 - 150 days after the patients received anti-TB drugs. One patients had positive serology markers for $\mathrm{HBV}$ (positive result for $\mathrm{HBs} \mathrm{Ag}$ and PCR-HBV tests). Nobody was positive for HCV or HIV. Two patients had diabetes mellitus. Among the patients with DIH, one patients were treated with five anti-TB drugs because of relapse or treatment failure; $47 \%$ had ALT, AST $\geq 6$ times of ULN. These patients had loss of appetite (80\%), icterus $(20 \%)$, nausea $(80 \%)$, vomiting $(50 \%)$, malaise $(45 \%)$, right upper quadrant tenderness $(24 \%)$, and loss of consciousness $(2 \%)$. Liver enzyme levels were normal after four to 30 days. No death was occurred. The mean of hospitalization duration was 11 days.

Table 1:Baseline characteristics \& frequency of patients according to side effects experienced by the patients.

\begin{tabular}{|l|l|}
\hline Parameters & Frequency of Patients (\%) \\
\hline Males & $46 \%$ \\
\hline Females & $54 \%$ \\
\hline Cough & $96 \%$ \\
\hline Fever & $80 \%$ \\
\hline Weight loss & $65 \%$ \\
\hline Breathlessness & $55 \%$ \\
\hline Hemoptysis & $5 \%$ \\
\hline Chest pain & $60 \%$ \\
\hline Loss of appetite & $80 \%$ \\
\hline Category-I & $87 \%$ \\
\hline Category-II & $13 \%$ \\
\hline Alcohol & $7 \%$ \\
\hline Smoking & $55 \%$ \\
\hline Nausea & $80 \%$ \\
\hline Gastritis & $60 \%$ \\
\hline Vomiting & $50 \%$ \\
\hline Joint pain & $7 \%$ \\
\hline Headache & $3 \%$ \\
\hline Depression & $12 \%$ \\
\hline Icterus & $20 \%$ \\
\hline Malaise & $45 \%$ \\
\hline Loss of consciousness & $2 \%$ \\
\hline
\end{tabular}

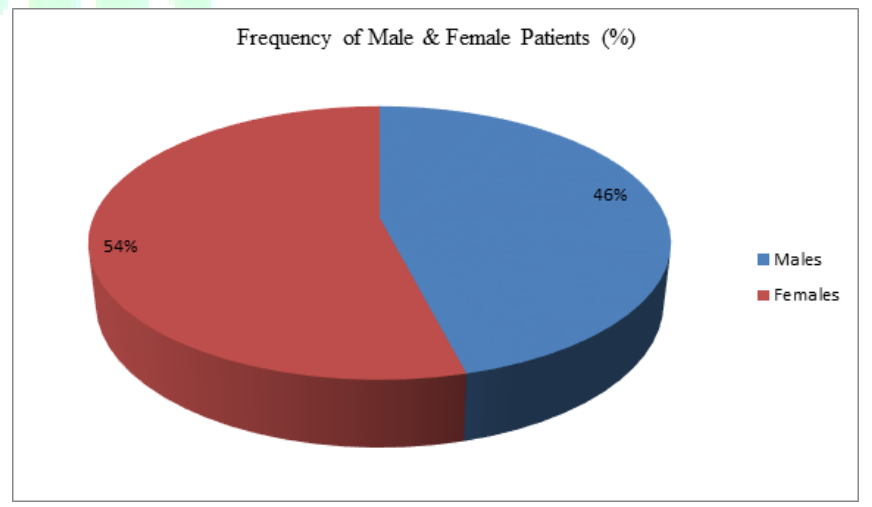

Figure 1: shows the frequency of male and female patients.

In the present study pattern of alteration of liver enzymes was evaluated. The current study showed that $19.4 \%$ of the patients with TB treated with anti-TB drugs faced hepatotoxicity. Drug-induced hepatotoxicity is one of the most important side effects of anti-TB treatment, which varies in different countries and the incidence various from $1 \%$ to $31 \%$. $^{[12-17]}$ Frequency is higher in countries like turkey $(18 \%)$, while it is lower in Western countries $(<1 \%$ in USA, 3.3\% in Spain, and 4\% in UK and 5.5\% in Iran). ${ }^{[13-}$

${ }^{17]}$ Depending on the factors such as geographical location, 
genetic factors, age, race, poor nutritional status, high alcohol use, extensive disease, pre-existing liver disease, hepatitis B and C, hepatitis B carriage, hypoalbuminaemia and acetylated status, the frequency was demonstrated to be different. ${ }^{[12,13]}$ Higher incidence of hepatotoxicity in older age may be secondary to the increased prevalence of co morbid disorders as well as use of related additional drugs in this age group. ${ }^{[12]}$ In the current study, $67 \%$ of the patients were more than 51 years. It was reported that the administration of rifampicin in a multidrug treatment regimen increased the incidence of significant hepatotoxicity among adults from $2.7 \%$ to $3.55 \% .{ }^{[15]}$ Pyrazinamide also contributed to increased incidence or severity of hepatotoxicity. In the current study patients received the standard regimen (combination of Isoniazid, rifampicin, pyrazinamide, and ethambutol \pm streptomycin). Extensive Tuberculosis itself may be a risk factor for Tuberculosis DIH. ${ }^{[13-15]}$ Based on medical records, nearly one-third of the patients with hepatitis also show an Extensive Tuberculosis on chest X-ray. In such situation, close follow-up is required during treatment with periodical clinical controls and laboratory tests. It is recommended that patients with TB be evaluated for hepatotoxicity by medical history, physical examination, laboratory tests, and they should also be aware of hepatotoxicity and hepatitis symptoms such as loss of appetite, nausea, vomiting, icterus, and abdominal pain and precautions for use of alcohol and other hepatotoxic drugs. ${ }^{[18-22]}$ According to the World Health Organization (WHO) recommendations, if the diagnosis is drug-induced hepatitis, the anti-TB drugs should be stopped until the normalization of the liver function tests. In the present study treatment was re-initiated only after normalization of liver enzymes. In the clinical practice, in drug related hepatotoxicity a step-by-step treatment approach was re-started by exclusion of responsible drug/s from the treatment regimen. Although, higher recurrence rate of hepatotoxicity in the retreatment of TB with a full-dose regimen including pyrazinamide is higher than regimen without this drug, ${ }^{[21,22]}$ the current study attempted to re-start all four drugs if possible; the purpose is mainly to observe Multiple Drug Resistance (MDR) and pre-extensively drug-resistant $\mathrm{TB}$ in this region. ${ }^{[23]}$

\section{Conclusion}

In conclusion, the prevalence of oral lesions such as fissured tongue and geogIn conclusion, the frequency of drug-induced hepatitis in the current study was Higher than those of other studies, simi $\neg$ lar to other reports, most of the TB cases in which hepa-totoxicity developed occurred in the subjects above 51 years old and a lot of them occurred after the first month of treatment. It should be considered that these cases require careful clinical and laboratory monitor $\neg$ ing. Priorities for future studies include basic studies to define genetic risk factor, the mechanism of antiTB drug-induced hepatotoxicity, and the development of safer TB drug regimens. Early diagnosis and identification of the risk factors for DILI is important to prevent hepatitisinduced mortality.

\section{References}

1. Global Tuberculosis Control: WHO Report 2011. World Health Organisation; 2011. viii, 246 p.

2. Schaberg T, Rebhan K, Lode H. Risk factors for side-effects of isoniazid, rifampin and pyrazinamide in patients hospitalized for pulmonary tuberculosis. EurRespir J. 1996;9:2026-2030.

3. Yee D, Valiquette C, Pelletier M, Parisien I, Rocher I, Menzies D. Incidence of serious side effects from first-line antituberculosis drugs among patients treated for active tuberculosis. Am J RespirCrit Care Med. 2003;167(11):1472-7.

4. Burman WJ, Reves RR. Hepatotoxicity from rifampin plus pyrazinamide: lessons for policymakers and messages for care providers. Am J RespirCrit Care Med. 2001;164(7):1112-3.

5. Tostmann A, Boeree MJ, Aarnoutse RE, de Lange WC, van der Ven AJ, Dekhuijzen R. Antituberculosis drug-induced hepatotoxicity: concise up-to-date review. J GastroenterolHepatol. 2008;23(2):192-202.

6. Larrey D. Epidemiology and individual susceptibility to adverse drug reactions affecting the liver. Semin Liver Dis. 2002;22(2):145-55.

7. Tost JR, Vidal R, Cayla J, Diaz-Cabanela D, Jimenez A, Broquetas JM, et al. Severe hepatotoxicity due to anti-tuberculosis drugs in Spain. Int J Tuberc Lung Dis. 2005;9(5):534-40.

8. Kiter G, Coskunol I. Hepatotoxicity during the anti-tuberculosis treatment: a retrospective survey of 5-year-period. 2000;48:20-5.

9. Steele MA, Burk RF, DesPrez RM. Toxic hepatitis with isoniazid and rifampin. A meta-analysis. Chest. 1991;99(2):465-71.

10. Sistanizad M, Azizi E, Khalili H, Hajiabdolbaghi M, Gholami K, Mahjub R. Antituberculosis Drug-Induced Hepatotoxicity in IranianTuberculosis Patients: Role of Isoniazid Metabolic Polymorphism. Iran J Pharm Res. 2011;10(3):633-9.

11. Khalili H, Dashti-Khavidaki S, Rasoolinejad M, Rezaie L, Etminani M. Anti-tuberculosis drugs related hepatotoxicity; incidence, risk factors, pattern of changes in liver enzymes and outcome. J Pharm Sci. 2009;17(3):163-7.

12. Larrey D. Epidemiology and individual susceptibility to adverse drug reactions affecting the liver. Semin Liver Dis. 2002;22(2):145-55.

13. Tost JR, Vidal R, Cayla J, Diaz-Cabanela D, Jimenez A, Broquetas JM, et al. Severe hepatotoxicity due to anti-tuberculosis drugs in Spain. Int J Tuberc Lung Dis. 2005;9(5):534-40.

14. Kiter G, Coskunol I. Hepatotoxicity during the anti-tuberculosis treatment: a retrospective survey of 5-year-period. 2000;48:20-5.

15. Steele MA, Burk RF, DesPrez RM. Toxic hepatitis with isoniazid and rifampin. A meta-analysis. Chest. 1991;99(2):465-71.

16. Sistanizad M, Azizi E, Khalili H, Hajiabdolbaghi M, Gholami K, Mahjub R. Antituberculosis Drug-Induced Hepatotoxicity in IranianTuberculosis Patients: Role of Isoniazid Metabolic Polymorphism. Iran J Pharm Res. 2011;10(3):633-9.

17. Khalili H, Dashti-Khavidaki S, Rasoolinejad M, Rezaie L, Etminani M. Anti-tuberculosis drugs related hepatotoxicity; incidence, risk factors, pattern of changes in liver enzymes and outcome. J Pharm Sci. 2009; 17(3):163-7.

18. Dossing M, Wilcke JT, Askgaard DS, Nybo B. Liver injury during antituberculosis treatment: an 11-year study. Tuber Lung Dis. 1996;77(4):335-40.

19. Huang YS, Chern HD, Su WJ, Wu JC, Lai SL, Yang SY, et al. Polymorphism of the $\mathrm{N}$-acetyltransferase 2 gene as a susceptibility risk factor for antituberculosis drug-induced hepatitis. Hepatology. 2002;35(4):883-9.

20. Shakya R, Rao BS, Shrestha B. Incidence of hepatotoxicity due to antitubercular medicines and assessment of risk factors. Ann Pharmacother. 2004;38(6):1074-9.

21. Teleman MD, Chee CB, Earnest A, Wang YT. Hepatotoxicity of tuberculosis chemotherapy under general programme conditions in Singapore. Int J Tuberc Lung Dis. 2002;6(8):699-705.

22. Hwang SJ, Wu JC, Lee CN, Yen FS, Lu CL, Lin TP, et al. A prospective clinical study of isoniazid-rifampicin-pyrazinamide-induced liver injury in an area endemic for hepatitis B. J GastroenterolHepatol. 1997;12(1):87-91. 
23. Metanat M, Sharifi-Mood B, Shahreki S, Dawoudi SH. Prevalence of

Red Crescent Med J. 2012;14(1):53-5. multidrug-resistant and extensively drug-resistant tuberculosis in patients with pulmonary tuberculosis in zahedan, southeastern iran. Iran

Copyright: (C) the author(s), 2019. It is an open-access article distributed under the terms of the Creative Commons Attribution License (CC BY 4.0), which permits authors to retain ownership of the copyright for their content, and allow anyone to download, reuse, reprint, modify, distribute and/or copy the content as long as the original authors and source are cited.

How to cite this article: Dhania O. Evaluation of Risk Factors and Changes in Liver Enzymes among the Patients with Antituberculosis DrugInduced Hepatitis: A Teaching Hospital Based Study. Asian J. Med. Res. 2019;8(2):PM01-PM04.

DOI: dx.doi.org/10.21276/ajmr.2019.8.2.PM1

Source of Support: Nil, Conflict of Interest: None declared. 